\title{
Non-volcanic seismic swarm and fluid transportation driven by subduction of the Philippine Sea slab beneath the Kii Peninsula, Japan
}

\author{
Aitaro Kato ${ }^{1,2^{*}}$, Atsushi Saiga ${ }^{3}$, Tetsuya Takeda ${ }^{4}$, Takaya Iwasaki ${ }^{2}$ and Toru Matsuzawa ${ }^{5}$
}

\begin{abstract}
To understand the mechanism of an intensive non-volcanic seismic swarm in the Kii Peninsula, Japan, we used a dense seismic linear array to measure fine-scale variations of seismic velocities and converted teleseismic waves. A low-velocity anomaly confined to just beneath the seismic swarm area is clearly imaged, which correlates spatially with an uplifted surface area and a highly conductive and strong attenuative body. These results suggest that fluids such as partial melt or water are present beneath this non-volcanic seismic swarm area. It is notable that the island arc Moho below the seismic swarm area is at a depth of approximately $32 \mathrm{~km}$ in the northern part of the seismic swarm area and shallows to approximately $20 \mathrm{~km}$ towards the south, due to the raised structure of the serpentinized mantle wedge. In addition, we show that the hydrated oceanic crust of the subducting Philippine Sea slab is characterized by low velocities with a high Poisson's ratio at depths of less than $40 \mathrm{~km}$. In contrast, dehydration conversion from oceanic basalt to eclogite takes place at depths greater than $50 \mathrm{~km}$. Water released from the subducting oceanic crust could cause serpentinization of the mantle wedge and infiltration into the forearc base of the overlying plate. The interaction between dehydration of the subducting oceanic crust and hydration of the mantle wedge and overlying plate exerts an important role in driving the non-volcanic seismic swarm activity in the Kii Peninsula.
\end{abstract}

Keywords: Non-volcanic seismic swarm; Fluid; Dehydration of oceanic crust; Serpentinized mantle wedge

\section{Findings}

\section{Introduction}

Based on the recent earthquake catalog created by stateof-the-art monitoring, many seismic swarms far from volcanoes have been identified worldwide that are characterized by spatial and temporal clustering (e.g., Vidale and Shearer 2006; Daniel et al. 2011; Chen et al. 2012). Well-determined hypocenters of non-volcanic seismic swarms have revealed that earthquakes migrate according to a diffusion equation during each sequence. Thus, the most plausible mechanism for driving non-volcanic seismic swarm activity has been linked to fluctuations or

\footnotetext{
* Correspondence: aitaro@seis.nagoya-u.ac.jp

${ }^{1}$ Earthquake and Volcano Research Center, Graduate School of Environmental Studies, Nagoya University, Furo-cho, Chikusa-ku, Nagoya 464-8601, Japan

${ }^{2}$ Earthquake Research Institute, University of Tokyo, 1-1-1 Yayoi, Bunkyo-ku, Tokyo 113-0032, Japan

Full list of author information is available at the end of the article
}

increases in fluid pressures at seismogenic depths (e.g., Hainzl 2004; Vidale and Shearer 2006; Kato et al. 2006, 2010a; Chen et al. 2012; Hainzl et al. 2012). However, the principal structural elements associated with the driving force for non-volcanic seismic swarms and hydration of the mantle wedge and overlying plate are less well documented because of a lack of high-resolution seismic structures, even though this knowledge is crucial in assessing the mechanisms of non-volcanic seismic swarms.

One of the most intensive non-volcanic seismic swarms in Japan is located in the Wakayama district of southwest Japan, far from the present volcanic front (e.g., Mizoue et al. 1983; Kato et al. 2010a; Yoshida et al. 2011) (Figure 1). Here, the Philippine Sea slab is subducting from a southeast-south direction beneath the Kii Peninsula. The swarm activity was initiated more than 40 years ago and has continued to the present day. The earthquake swarm consists of numerous shallow earthquake clusters $(<10-\mathrm{km}$ 


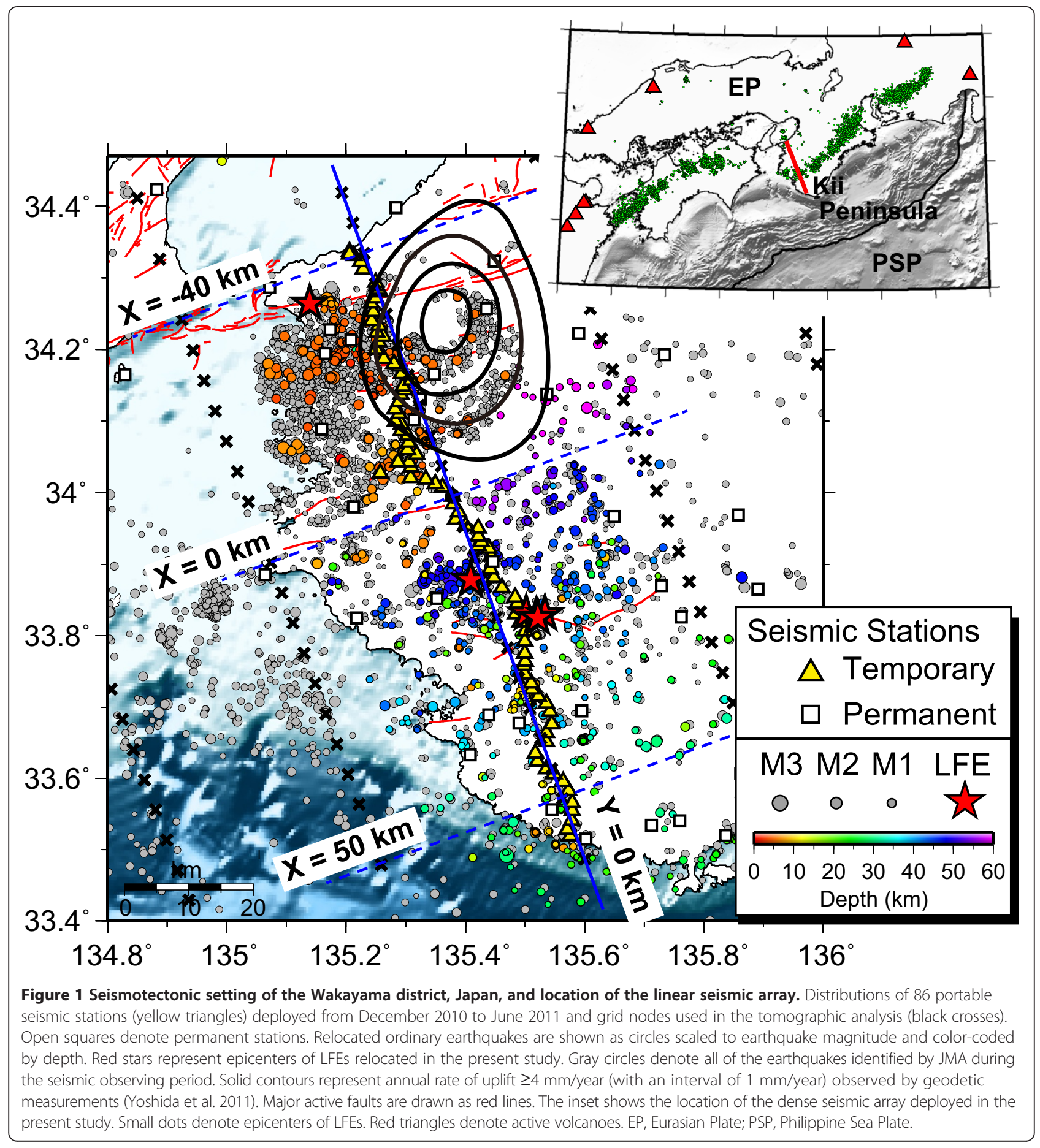

depth) and is spatially confined to an area of approximately $30 \times 30 \mathrm{~km}^{2}$ around the western edge of the Kii Peninsula (Figure 1). The occurrence rate of earthquakes with magnitudes greater than 3.0 is $>10$ events/year.

In addition, the Wakayama district has unique geophysical characteristics such as high heat flow (Tanaka et al. 2004), uplift movement on the surface that implies a pressurized source (Yoshida et al. 2011), and deep low- frequency earthquakes (LFEs) around the island arc Moho. Kato et al. (2010a) proposed that diorite has intruded into the bottom of the seismic swarm area and that fluids released from the solidifying diorite are invading the rocks immediately above, based on a local seismic tomographic image of the southern edge of the seismic swarm area.

To investigate the principal seismic structural elements linked to the non-volcanic seismic swarm and subduction 
complex associated with the Philippine Sea slab, we deployed a temporary, dense linear array consisting of 86 portable seismic stations extending $100 \mathrm{~km}$, from the southern to the northern edge of the western Kii Peninsula, which crosscuts the Wakayama region (Figure 1). Seismic tomography and receiver function techniques combined with such a dense linear array are powerful tools for imaging high-resolution seismic structural elements, as well determining precise hypocenter solutions, including LFEs (e.g., Kato et al. 2009; Kato et al. 2010b). These data enable us to investigate the detailed velocity structure with higher spatial resolution, from 3 to $5 \mathrm{~km}$, and constrain the key factors driving the non-volcanic seismic swarm and dehydration within the oceanic crust of the subducting Philippine Sea slab.

\section{Data and methods}

The dense seismic observations were conducted from December 2010 to June 2011 (Figure 1). The linear array consisted of 86 seismometers with a $1-\mathrm{Hz}$ natural frequency, continuously recording three-component signals at a sampling rate of 200 or $100 \mathrm{~Hz}$. Both P- and S-wave arrival times from 776 ordinary earthquakes and 6 LFEs listed in the Japan Meteorological Agency (JMA) catalog were manually picked from waveforms observed by dense temporary stations as well as permanent stations. The initial hypocenter locations for the tomographic analysis were determined by applying a maximum likelihood estimation algorithm (Hirata and Matsu'ura 1987) to the observed arrival times. We used a one-dimensional velocity structure with a $V_{\mathrm{p}} / V_{\mathrm{s}}$ value of 1.73 (Kato et al. 2010a), which has been used for routine hypocenter determinations at the Wakayama Observatory of the Earthquake Research Institute. The location errors of the initial hypocenters were estimated to be 0.2 and $0.25 \mathrm{~km}$ for the horizontal and vertical directions, respectively.

\section{Seismic tomography}

The double-difference tomography method (Zhang and Thurber 2003) was then applied to the arrival time data. The number of absolute $\mathrm{P}$ - and $\mathrm{S}$-wave arrival times was 47,785 and 43,155 , with the differential arrival times for manually picked $\mathrm{P}$ and $\mathrm{S}$ waves reaching 257,416 and 225,281 , respectively. We also included more accurate differential arrival times obtained by the waveform cross-correlation method, which contained 100,358 P-wave and 59,356 S-wave observations. These have a normalized cross-correlation coefficient exceeding 0.8 . The grid nodes for the tomography analysis are located at $-300,-100,-80,-60,-50,-45,-40,-35$, $-30,-25,-20,-15,-10,-5,0,5,10,15,20,25,30,35$, $40,45,50,60,80,100$, and $300 \mathrm{~km}$ on the $X$-axis (E65S; subparallel to the linear array); $-300,-90,-60,-30,0$, $30,60,90$, and $300 \mathrm{~km}$ on the $Y$-axis (N65E); and -150 ,
$0,3,6,9,12,15,19,24,29,34,39,44,49,54,74,94$, and $300 \mathrm{~km}$ on the $Z$-axis (depth) (Figure 1). The initial velocity structure used for tomographic analysis is the same as that employed for the hypocenter determinations. The root-mean-square (RMS) travel time residual was reduced from 0.086 to $0.048 \mathrm{~s}$ after 18 iterations.

We conducted several tests to evaluate the model resolutions (Figure 2). We had initially conducted a checkerboard resolution test using perturbations of $\pm 5 \%$ from the initial velocity model. Synthetic travel times were then calculated for this checkerboard model, adding random noises uniformly distributed from -0.05 to $0.05 \mathrm{~s}$ for the $\mathrm{P}$ wave and from -0.1 to $0.1 \mathrm{~s}$ for the $\mathrm{S}$ wave. We then estimated the model resolution of the tomography (diagonal element values) using the solution technique in the simul2000 algorithm (Thurber and Eberhart-Phillips 1999), using only the absolute arrival times. Since we do not include the double-difference data in estimating the resolution, simul2000 might underestimate the actual model resolution (Thurber et al. 2007). We see in Figure 2 that most of the model areas have very good resolution, as estimated from the resolution diagonal element values that were greater than 0.5 , between the surface and the band of intraslab earthquakes. We masked poor resolution areas with gray in the depth sections of the velocity perturbations (Figure 2).

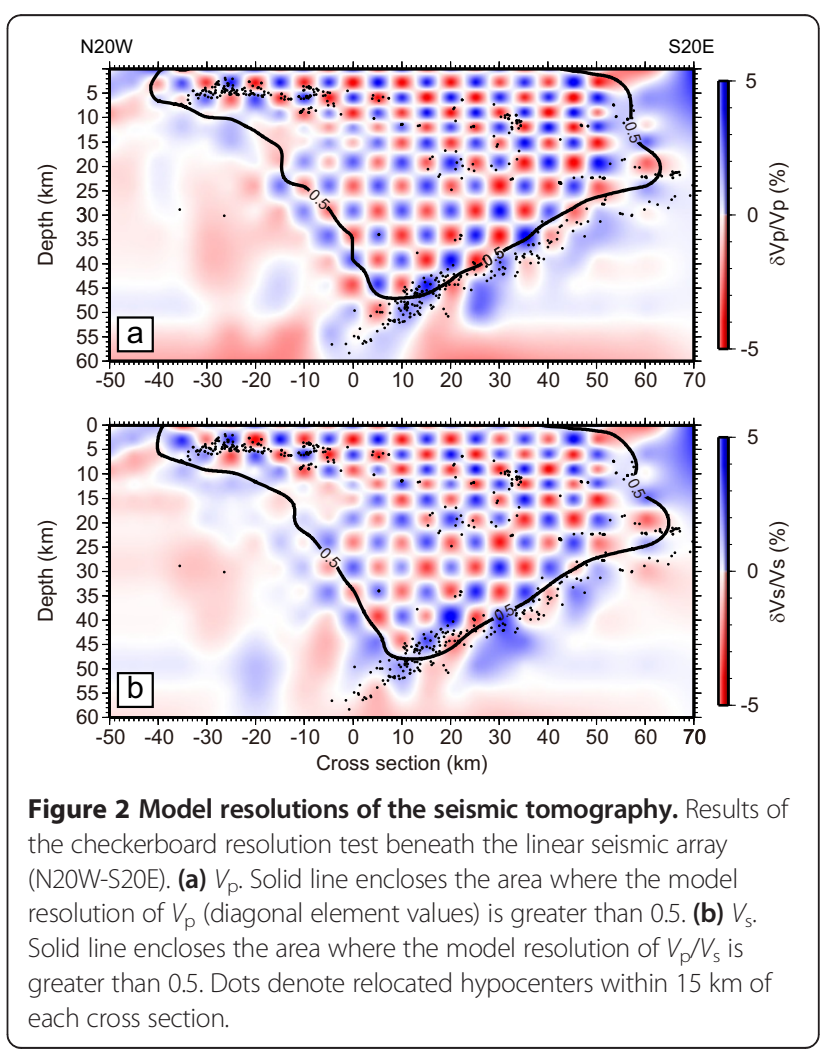




\section{Receiver function}

We calculated receiver functions using teleseismic waveforms recorded by the linear seismic array. After individual waveforms of teleseismic earthquakes $(M \geq 5.0$ and angular distances from $30^{\circ}$ to $90^{\circ}$, Figure 3 ) were visually inspected, a total of 2,621 waveforms with clear P-wave onsets and high signal-to-noise ratios were accepted for further analysis. We isolated the incident $\mathrm{P}$ wave by transforming the accepted waveforms to wave-vector space using the freesurface transfer matrix (Kennett 1991). We then calculated receiver functions using teleseismic waveforms along the linear array, applying the spectral division (Ammon 1991) method with a water level fraction of 0.001 and Gaussian filter width of 3.0 (approximately $1.5-\mathrm{Hz}$ low-pass filters). The time series of the receiver functions were converted to depth sections by applying a form of migration to each event-station pairing, where each receiver function is repositioned to the predicted location of the P-S converted phases assuming a one-dimensional velocity model for each station. The one-dimensional velocity model beneath each station was constructed from interpolation of the final tomography model (Figure $4 \mathrm{~b}, \mathrm{c}$ ). The depth section of each receiver function was represented by a bending ray with a ray parameter and back azimuth. The individual migrated receiver functions were then stacked onto $1 \mathrm{~km}$ by $1 \mathrm{~km}$ cells along the seismic array profile.



Figure 3 Epicenter distribution of teleseismic earthquakes. They were used in the receiver function analysis shown as circles color-coded by depth.

\section{Results and discussions}

We focus here on the seismic structural elements identified by the dense linear array, from the perspective of understanding the processes responsible for the non-volcanic seismic swarm and dehydration within the oceanic crust of the subducting Philippine Sea slab.

\section{Low-velocity anomaly beneath the non-volcanic seismic swarm area}

The most striking feature of the seismic image is a lowvelocity anomaly confined to just beneath the Wakayama seismic swarm area (LV1 in Figure 4). The depths of relocated hypocenters gradually decrease towards the center of the swarm area, forming a dome-like shape. It should be noted that the dome-like shape of the hypocenters correlates well with the uplift pattern on the surface (Figure 4a). Given that the cutoff depth of crustal earthquakes implies that temperatures reach approximately $350^{\circ} \mathrm{C}$, corresponding to the brittle-ductile transition of granitic rock (e.g., Ito 1990; Kato et al. 2003), the domelike hypocenter distribution might be controlled by the isothermal structure generated by the low-velocity anomaly. The minimum cutoff depth of seismicity is less than $6 \mathrm{~km}$ at the center of the swarm area, which indicates a higher thermal gradient compared to the forearc region where crustal earthquakes extend to depths of approximately $25 \mathrm{~km}$.

Although the spatial resolution of the velocity model is not particularly well constrained below the seismic swarm area due to poor coverage of seismic rays, the low-velocity anomaly (LV1) appears to extend deeper, perhaps close to the island arc Moho and mantle wedge corner. The deep extension of the low-velocity anomaly is supported by the receiver function analysis, which shows relatively strong negative polarities beneath the seismic swarm area (Figure 4f). Within this velocity anomaly (LV1), the reduction of $V_{\mathrm{p}}$ is larger than that of $V_{\mathrm{s}}$, resulting in a low $V_{\mathrm{p}} / V_{\mathrm{s}}$ ratio of approximately 1.64 (Figure $4 \mathrm{e}$ ). The corresponding Poisson's ratio is 0.20 , which is substantially smaller than $V_{\mathrm{p}} / V_{\mathrm{s}}$ ratios measured for most common crustal rocks in laboratory experiments, except for quartzite (e.g., Christensen 1996). There are two candidates that can explain a low-velocity anomaly with a low Poisson's ratio beneath the seismic swarm area. The first possibility is the presence of fluids such as water or partial melt trapped in the cracks or pores, and the second explanation is the presence of quartz-rich rock. Based on theoretical studies for saturated cracked solids filled with water (e.g., O'Connell and Budiansky 1974; Shearer 1988; Takei 2002; Lin and Shearer 2009), waterfilled cracks with high aspect ratios $(>0.1)$ can produce $V_{\mathrm{p}} / V_{\mathrm{s}}$ ratios as low as 1.64 , in which case the porosity would be around 10\% (see Figure three (a) in Lin and Shearer (2009)). Low $V_{\mathrm{p}} / V_{\mathrm{s}}$ ratio anomalies have been 


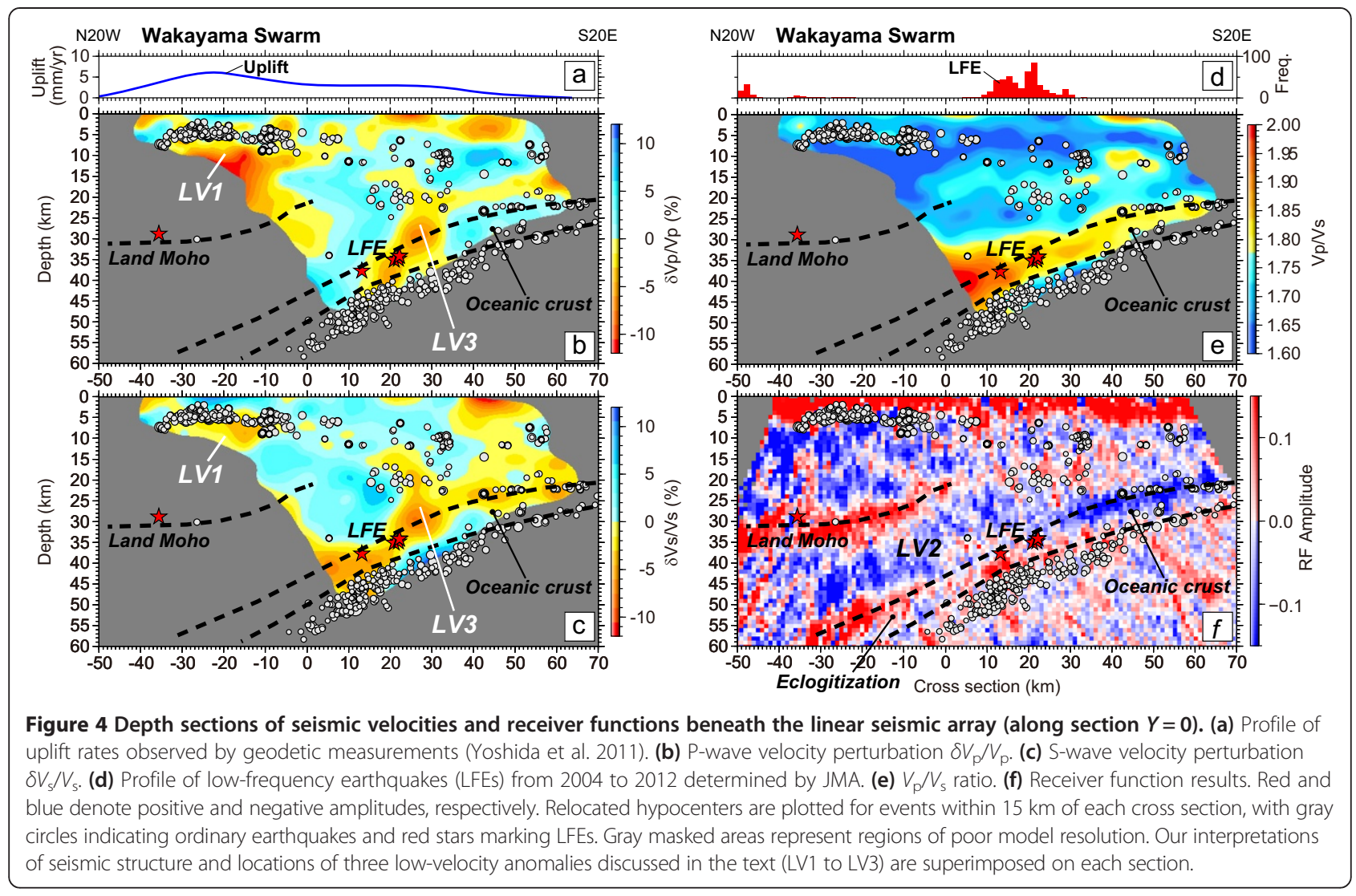

widely observed in volcanic and geothermal areas (e.g., Nakajima et al. 2001; Reyners et al. 2007), beneath the northern Fossa Magna Basin in central Japan (Kurashimo and Hirata 2004), and in southern California (Lin and Shearer 2009). These low $V_{\mathrm{p}} / V_{\mathrm{s}}$ ratio anomalies have been interpreted as indicating the presence of water.

A wideband magnetotelluric survey conducted in the southern part of the Wakayama region showed that a highly conductive body appears to be present beneath the seismic swarm area (Uyeshima et al. 2010). In addition, a seismic attenuation study has imaged a strong attenuation body beneath the Wakayama seismic swarm area (Umeyama et al. 2013), which spatially coincides with the low-velocity anomaly (LV1) imaged by our study. Given that it is difficult to explain high conductivity and strong attenuation features with only quartz-rich rock, we prefer a model where fluid-filled cracks with high aspect ratios are present beneath the seismic swarm area. Indeed, a deep LFE relocated near the island arc Moho beneath the Wakayama region $(X \sim-35 \mathrm{~km}$, Figure 4$)$ implies the involvement of fluid near the base of the crust.

Combined with these observations, the long-term persistence of the dome-like pattern of seismicity (Yoshida et al. 2011; Japan Meteorological Agency 2014) and the pressurized source producing uplift and dilatation at the surface (Figure 1) indicate that fluids such as water or partial melt beneath the seismic swarm area are key factors driving the seismic swarm activity (Figure 5).

It is notable that the island arc Moho as defined by the strong positive amplitude of the receiver function is located at depths of approximately $32 \mathrm{~km}$ in the northern part of the seismic swarm area and approximately $20 \mathrm{~km}$ towards the southern part of the area (Figure 4f). This strong lateral variation of the Moho depth is linked to the structure of the mantle wedge corner and will be discussed later in this paper.

\section{Dehydration processes within subducting oceanic crust}

In Figure 4f, we see that the top and bottom of the subducting oceanic crust (i.e., plate interface and oceanic Moho) are defined by strong negative and positive amplitudes of receiver functions, respectively. At depths greater than $40 \mathrm{~km}$, a depth section of receiver functions shows that the oceanic crust is subducting with a dip angle of approximately $15^{\circ}$. Intraslab earthquakes dipping parallel to the oceanic crust are distributed near the Moho of the subducting oceanic crust. The subducting oceanic crust at depths of less than $40 \mathrm{~km}$ is generally characterized by relatively low velocities and a high $V_{\mathrm{p}} / V_{\mathrm{s}}$ ratio, as shown by the seismic tomography and receiver functions (Figure 4). We interpret this as indicating water trapped within the oceanic sedimentary layer or released by progressive 


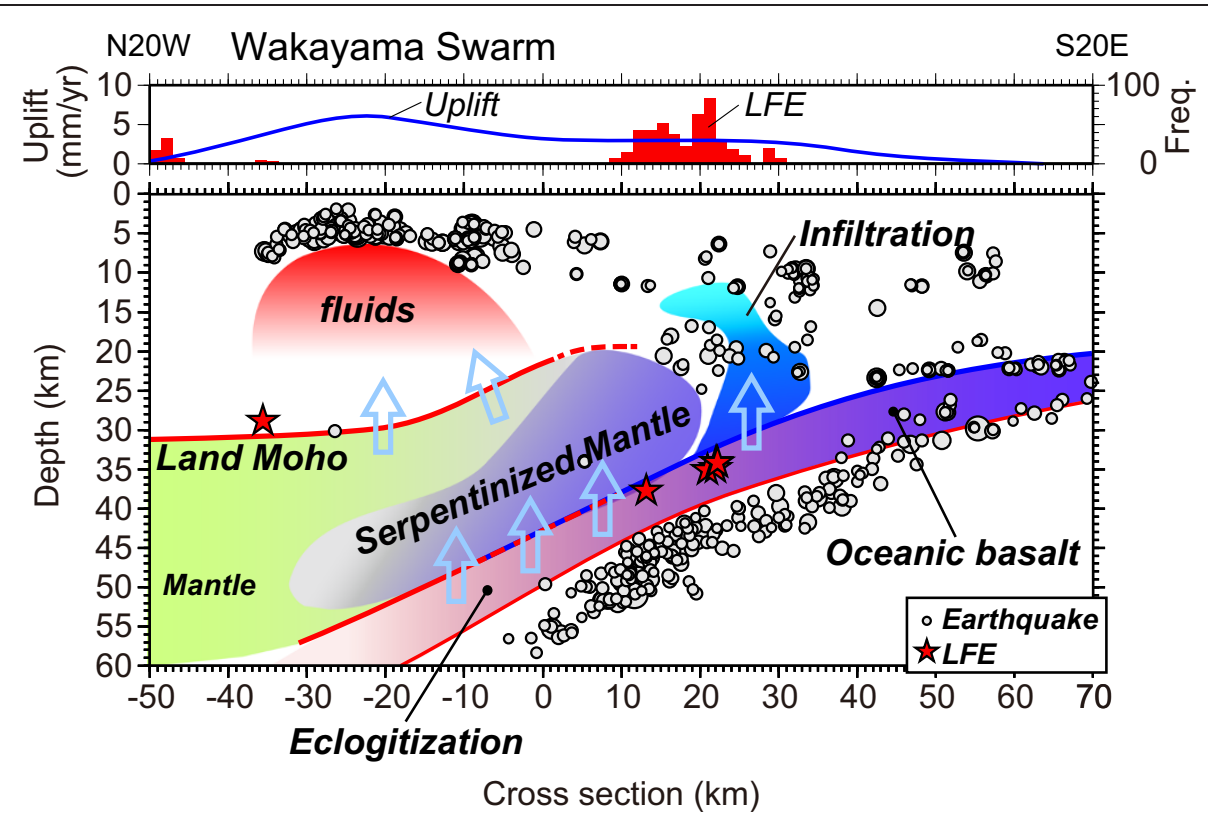

Figure 5 Schematic interpretations of the seismic structures beneath the Kii Peninsula. Light blue arrows denote potential water pathways in the subduction complex.

metamorphic dehydration reactions in the oceanic crust (e.g., Christensen 1984). Low-velocity layers within the oceanic crust representing trapped water have been widely identified in the Nankai, Cascadia, southern Mexico, and Costa Rica subduction zones (e.g., Hirose et al. 2008; Audet et al. 2009; Song et al. 2009; Kato et al. 2010b; Audet and Schwartz 2013).

In contrast, the polarity of the top plate interface changes from negative to positive at depths greater than $50 \mathrm{~km}$. The dip angle of the oceanic crust increases rapidly with depth, due to the initiation of slab bending. This initiation of slab bending is supported by the change in dip angle of the alignment of intraslab earthquakes located near the oceanic Moho (Figure 4). We interpret this transition of the polarities of receiver functions as marking the onset of eclogitization of hydrous minerals in oceanic basalt (e.g., Hacker et al. 2003) (Figure 5). Although the possibility of conversion from oceanic basalt to eclogite was possibly identified by seismic observations of coda waves trapped within the low-velocity oceanic crust layer (Fukao et al. 1983), our study provides a more direct and complete picture of the dehydration process within the oceanic crust. Based on a calculated thermal structure in the Kii Peninsula (Yoshioka et al. 2009), the conversion from oceanic basalt to eclogite at depths of 40 to $50 \mathrm{~km}$ is taking place at approximately $500^{\circ} \mathrm{C}$. Similar transitions in receiver function polarities due to the conversion from oceanic basalt to eclogite have been recognized in the Cascadia subduction zone (Abers et al. 2009) and Kyushu region (Abe et al. 2011).
Between the island arc Moho and subducting oceanic crust (mantle wedge), a northward dipping low-velocity anomaly represented as a negative amplitude is imaged by the receiver function (LV2 in Figure 4f). Due to the shallower extension of this low-velocity anomaly parallel to the dip direction of the oceanic crust, the island arc Moho shows a raised structure near the mantle wedge corner between $X=-10 \mathrm{~km}$ and $X=10 \mathrm{~km}$. We interpret this low-velocity anomaly in the mantle wedge to be due to a partial serpentinization of dry olivine (e.g., Pommier 2014). Indeed, a recent study using a dense seismic array on the western Kii Peninsula (Saiga et al. 2013) identified a 1- to 15-km-thick layer of seismic anisotropy in the mantle wedge, interpreted to be a serpentinized layer parallel to the dip direction of the plate interface. The serpentinization in the mantle might be caused by partial leakage of water into the mantle wedge corner released by dehydration associated with the formation of eclogite from basalt at depths greater than $50 \mathrm{~km}$ (Figure 5). Although it is difficult to identify the precise location of the toe of the mantle wedge corner $(X=10$ to $30 \mathrm{~km})$, both the receiver function and the seismic tomography suggest that there is a gradual transition from crustal to mantle material therein.

Interestingly, relocated LFEs on the forearc side $(X=10$ to $30 \mathrm{~km}$ ) align along the plate interface around the onset of contact between the serpentinized mantle wedge and the top of the subducting oceanic crust. Similar features were observed in a study that imaged the fine-scale seismic structures in the Tokai district, Japan (e.g., Kato 
et al. 2010b). These observations suggest that serpentinite layers in the mantle wedge corner may be important for generating LFEs in subduction zones (Kaproth and Marone 2013), along with high fluid pressures within the oceanic crust.

We identified a vertically elongated low-velocity anomaly near the base of the forearc crust on the southern side of a zone of LFEs (LV3 in Figure 4). This low-velocity anomaly with a diapiric shape has a moderate $V_{\mathrm{p}} / V_{\mathrm{s}}$ ratio that appears to originate at the plate boundary, and is not associated with crustal earthquakes. Furthermore, this low-velocity anomaly corresponds to a highly conductive zone imaged by a wideband magnetotelluric survey crossing the present dense linear array at $X \sim 25 \mathrm{~km}$ (Umeda et al. 2006). It thus seems probable that some water leaking from the highly pressurized oceanic crust migrated upwards within the forearc crust. Similar vertically elongated anomalies originating in the oceanic crust have also been imaged in subduction complexes in New Zealand and the Tokai district, Japan (Wannamaker et al. 2009; Kato et al. 2010b). Therefore, water leakage from subducting oceanic crust into the mantle wedge and infiltration into the base of the forearc of the overlying plate are important in transporting and circulating water in subduction zones.

In summary, we propose that the mantle wedge and lower crust beneath the non-volcanic seismic swarm area are being hydrated by fluids released from dehydration of subducting oceanic crust (Figure 5). Fluids such as water or partial melt beneath the seismic swarm area are key factors driving the non-volcanic seismic swarm activity. On the forearc side, dehydrated water also appears to be infiltrating into the base of the overlying plate. These views are consistent with geochemical studies (e.g., Umeda et al. 2006) that have shown that ${ }^{3} \mathrm{He} /{ }^{4} \mathrm{He}$ ratios in the Kii Peninsula are anomalously high, which may be indicative of renewed or incipient magmatism.

Some aspects of the hydration process beneath the seismic swarm area still remain unclear and cannot be addressed within the framework of the present study because of the poor spatial resolution of the seismic tomographic image for depth variations. Further studies of the three-dimensional seismic structure imaged by a wider and denser network, along with detailed geological and laboratory studies, are needed to advance our understanding of the process.

\section{Conclusions}

Detailed variations of seismic velocities and converted teleseismic waves along a profile in the western part of the Kii Peninsula have shown that a low-velocity anomaly is confined to just beneath the seismic swarm area. This low-velocity anomaly correlates well spatially with an uplifted surface area and a highly conductive and strong attenuation body. These results suggest that fluids such as partial melt or water are present beneath the non-volcanic seismic swarm area and are key factors driving the nonvolcanic seismic swarm. The island arc Moho below the seismic swarm area is at a depth of approximately $32 \mathrm{~km}$ in the northern part of the seismic swarm area and shallows to approximately $20 \mathrm{~km}$ towards the south, due to a raised structure in the serpentinized mantle wedge corner. In addition, we have shown that the hydrated oceanic crust of the subducting Philippine Sea slab is characterized by low velocities with a high Poisson's ratio at depths $<40 \mathrm{~km}$. In contrast, dehydration conversion from oceanic basalt to eclogite takes place at depths $>50 \mathrm{~km}$. Water released from the subducting oceanic crust may be causing serpentinization of the mantle wedge and infiltrating into the forearc base of the overlying plate. It is likely that the non-volcanic seismic swarm in the Wakayama district is a manifestation of water transportation in the subduction system.

\section{Competing interests}

The authors declare that they have no competing interests.

\section{Authors' contributions}

AK carried out the seismic observation, data processing, phase picking, and analysis of the data, and drafted the manuscript. AS carried out the seismic observation and phase picking and helped to draft the manuscript. $\pi$ participated in the seismic observation and helped to draft the manuscript. $\mathrm{TI}$ participated in the seismic observation and coordination and helped to draft the manuscript. TM performed the coordination and helped to draft the manuscript. All authors read and approved the final manuscript.

\section{Acknowledgements}

We thank anonymous reviewers for useful comments and suggestions. We are grateful to T. Haneda, M. Serizawa, M. Saka, S. Watanabe, K. Tagami, and M. Kobayashi for data acquisition. We thank NIED and JMA for allowing us to use waveform data collected from their permanent stations. JMA provided us with the earthquake catalog. This study was supported by the Ministry of Education, Culture, Sports, Science, and Technology of Japan, under KAKEN (21109002) and its Observation and Research Program for Prediction of Earthquakes and Volcanic Eruptions.

\section{Author details}

${ }^{1}$ Earthquake and Volcano Research Center, Graduate School of Environmental Studies, Nagoya University, Furo-cho, Chikusa-ku, Nagoya 464-8601, Japan. ${ }^{2}$ Earthquake Research Institute, University of Tokyo, 1-1-1 Yayoi, Bunkyo-ku, Tokyo 113-0032, Japan. ${ }^{3}$ Geological and Seismological Analysis Group, FBR Safety Technology Center, Japan Atomic Energy Agency, 2-1 Shiraki, Tsuruga, Fukui 919-1279, Japan. ${ }^{4}$ National Research Institute for Earth Science and Disaster Prevention, 3-1 Tennodai, Tsukuba-shi, Ibaraki 305-0006, Japan. ${ }^{5}$ Research Center for Prediction of Earthquakes and Volcanic Eruptions, Graduate School of Science, Tohoku University, 6-6 Aza-Aoba, Aramaki, Aoba-ku, Sendai 980-8578, Japan.

Received: 14 November 2013 Accepted: 21 July 2014

Published: 4 August 2014

\section{References}

Abe Y, Ohkura T, Hirahara K, Shibutani T (2011) Water transportation through the Philippine Sea slab subducting beneath the central Kyushu region, Japan, as derived from receiver function analyses. Geophys Res Lett 38, L23305. doi:10.1029/2011GL049688

Abers GA, MacKenzie LS, Rondenay S, Zhang Z, Wech AG, Creager KC (2009) Imaging the source region of Cascadia tremor and intermediate-depth earthquakes. Geology 37:1119-1122. doi:10.1130/G30143A.1 
Ammon CJ (1991) The isolation of receiver function effect from teleseismic P waveforms. Bull Seismol Soc Am 81(6):2504-2510

Audet P, Bostock MG, Christensen NI, Peacock SM (2009) Seismic evidence for overpressured subducted oceanic crust and megathrust fault sealing. Nature 457:76-78

Audet P, Schwartz SY (2013) Hydrologic control of forearc strength and seismicity in the Costa Rican subduction zone. Nat Geosci 6(10):852-855

Chen X, Shearer PM, Abercrombie RE (2012) Spatial migration of earthquakes within seismic clusters in Southern California: evidence for fluid diffusion. J Geophys Res 117, B04301. doi:10.1029/2011JB008973

Christensen NI (1984) Pore pressure and oceanic crustal seismic structure. Geophys J Roy Astron Soc 79:411-423

Christensen NI (1996) Poisson's ratio and crustal seismology. J Geophys Res 101:3139-3156

Daniel G, Prono E, Renard F, Thouvenot F, Hainzl S, Marsan D, Helmstetter A, Traversa P, Got JL, Jenatton L, Guiguet R (2011) Changes in effective stress during the 2003-2004 Ubaye seismic swarm, France. J Geophys Res 116, B01309. doi:10.1029/2010JB007551

Fukao Y, Hori S, Ukawa M (1983) A seismological constraint on the depth of basalt-eclogite transition in a subducting oceanic crust. Nature 303:413-415

Hacker BR, Abers GA, Peacock SM (2003) Subduction factory: 1. Theoretical mineralogy, densities, seismic wave speeds, and $\mathrm{H}_{2} \mathrm{O}$ contents. J Geophys Res 108(B1):2029

Hainzl S (2004) Seismicity patterns of earthquake swarms due to fluid intrusion and stress triggering. Geophys J Int 159(3):1090-1096. doi:10.1111/j.1365246X.2004.02463.x

Hainzl S, Fischer T, Dahm T (2012) Seismicity-based estimation of the driving fluid pressure in the case of swarm activity in Western Bohemia. Geophys $\mathrm{J}$ Int 191:271-281. doi:10.1111/j.1365-246X.2012.05610.x

Hirata N, Matsu'ura M (1987) Maximum-likelihood estimation of hypocenter with origin time eliminated using nonlinear inversion technique. Phys Earth Planet Inter 47:50-61, doi:10.1016/0031-9201(87) 90066-5

Hirose F, Nakajima J, Hasegawa A (2008) Three-dimensional seismic velocity structure and configuration of the Philippine Sea slab in southwestern Japan estimated by double-difference tomography. J Geophys Res 113, B09315. doi:10.1029/2007JB005274

Ito K (1990) Regional variations of the cutoff depth of seismicity in the crust and their relation to heat flow and large inland earthquakes. J Phys Earth 38:223-250

Japan Meteorological Agency (2014). In: JMA unified hypocenter catalog. http:// www.data.jma.go.jp/svd/egev/data/bulletin/index.html. Accessed 10 June 2014

Kaproth BM, Marone C (2013) Slow earthquakes, preseismic velocity changes, and the origin of slow frictional stick-slip. Science 341:1229-1232. doi:10.1126/ science.1239577

Kato A, lidaka T, Sakai S, Hirata N, Kanazawa T (2006) Seismic swarm observed by high-resolution seismic experiment: role of crustal fluids. American Geophysical Union, Fall Meeting 2006, abstract \#T13A-0482

Kato A, Kurashimo E, Igarashi T, Sakai S, lidaka T, Shinohara M, Kanazawa T, Yamada T, Hirata N, Iwasaki T (2009) Reactivation of ancient rift systems triggers devastating intraplate earthquakes. Geophys Res Lett 36, L05301. doi:10.1029/2008GL036450

Kato A, Ohnaka M, Mochizuki H (2003) Constitutive properties for the shear failure of intact granite in seismogenic environments. J Geophys Res 108 (B1):2060. doi:10.1029/2001JB000791

Kato A, Sakai S, lidaka T, Iwasaki T, Hirata N (2010a) Non-volcanic seismic swarms triggered by circulating fluids and pressure fluctuations above a solidified diorite intrusion. Geophys Res Lett 37, L15302. doi:10.1029/2010GL043887

Kato A, lidaka T, Ikuta R, Yoshida Y, Katsumata K, Iwasaki T, Sakai S, Thurber C, Tsumura N, Yamaoka K, Watanabe T, Kunitomo T, Yamazaki F, Okubo M, Suzuki S, Hirata N (2010b) Variations of fluid pressure within the subducting oceanic crust and slow earthquakes. Geophys Res Lett 37, L14310. doi:10.1029/2010GL043723

Kennett BLN (1991) Removal of free surface interactions from three component seismograms. Geophys J Int 104:153-163

Kurashimo E, Hirata N (2004) Low Vp and Vp/Ns zone beneath the northern Fossa Magna basin, central Japan, derived from a dense array observation. Earth Planets Space 56:1301-1308

Lin G, Shearer PM (2009) Evidence for water-filled cracks in earthquake source regions. Geophys Res Lett 36, L17315. doi:10.1029/2009GL039098

Mizoue M, Nakamura M, Seto N, Ishiketa Y, Yokota T (1983) Three-layered distribution of microearthquakes in relation to focal mechanism variation in the Kii Peninsula southwestern Honshu, Japan. Bull Earthquake Res Inst Univ Tokyo 58:287-310
Nakajima J, Matsuzawa T, Hasegawa A, Zhao D (2001) Three dimensional structure of $V p, V s$, and $V p / v s$ beneath northeastern Japan: implications for arc magmatism and fluids. J Geophys Res 106:21,843-21,857

O'Connell RJ, Budiansky B (1974) Seismic velocities in dry and saturated cracked solids. J Geophys Res 79:5412-5426

Pommier A (2014) Geophysical assessment of migration and storage conditions of fluids in subduction zones. Earth Planets Space 66:38. doi:10.1186/1880-5981-66-38

Reyners M, Eberhart-Phillips D, Stuart G (2007) The role of fluids in lower-crustal earthquakes near continental rifts. Nature 446:1075-1078

Saiga A, Kato A, Kurashimo E, lidaka T, Okubo M, Tsumura N, Iwasaki T, Sakai S, Hirata N (2013) Anisotropic structures of oceanic slab and mantle wedge in a deep low-frequency tremor zone beneath the Kii Peninsula, SW Japan. J Geophys Res 118:1091-1097. doi:10.1002/jgrb.50069

Shearer PM (1988) Cracked media, Poisson's ratio, and the structure of the upper oceanic crust. Geophys J Int 92:357-362

Song TR, Helmberger DV, Brudzinski MR, Clayton RW, Davis P, Pérez-Campos X, Singh SK (2009) Subducting slab ultra-slow velocity layer coincident with silent earthquakes in southern Mexico. Science 324:502-506

Takei $Y$ (2002) Effect of pore geometry on VPNS: from equilibrium geometry to crack. J Geophys Res 107(B2):2043. doi:10.1029/2001JB000522

Tanaka A, Yamamoto M, Yano Y, Sasada M (2004) Geothermal gradient and heat flow data in and around Japan (I): appraisal of heat flow from geothermal gradient data. Earth Planets Space 56:1191-1194

Thurber CH, Brocher TM, Langenheim VE (2007) Three-dimensional P wave velocity model for the San Francisco Bay region, California. J Geophys Res 112, B07313. doi:10.1029/2006JB004682

Thurber CH, Eberhart-Phillips D (1999) Local earthquake tomography with flexible gridding. Comput Geosci 25:809-818

Umeda K, Ogawa Y, Asamori K, Oikawa T (2006) Aqueous fluids derived from a subducting slab: observed high ${ }^{3} \mathrm{He}$ emanation and conductive anomaly in a non-volcanic region, Kii Peninsula southwest Japan. J Volcanol Geotherm Res 149:47-61

Umeyama E, Tsumura N, Kurashimo E, lidaka T, Sakai S, Kato A, Saiga A (2013) Three-dimensional attenuation structure beneath Kii Peninsula. In: Programme and abstracts of the Seismological Society of Japan 2013. Fall meeting B21-06, Kanagawa Kenmin Hall, Yokohama, 7-9 October 2013 (in Japanese)

Uyeshima M, Yamaguchi S, Patro PK, Ogawa T, Kato A, Hasegawa K, Ueda T, Aizawa K, Hase H (2010) Wideband MT survey in Aridagawa nonvolcanic earthquake swarm area in NW Kii Peninsula. Paper presented at the conductivity anomaly conference, Tokyo, 16-17 February 2010 (in Japanese)

Vidale JE, Shearer PM (2006) A survey of 71 earthquake bursts across southern California: exploring the role of pore fluid pressure fluctuations and aseismic slip as drivers. J Geophys Res 111, B05312. doi:10.1029/2005JB004034

Wannamaker P, Caldwell TG, Jiracek GR, Maris V, Hill GJ, Ogawa Y, Bibby HM, Bennie SL, Heise W (2009) Fluid and deformation regime of an advancing subduction system at Marlborough, New Zealand. Nature 460:733-736. doi:10.1038/nature08204

Yoshida A, Hosono K, Takayama H, Kobayashi A, Maeda K (2011) Seismic and geodetic evidence for the existence of hot materials beneath the Wakayama swarm activity, southwestern Japan. Tectonophysics 510:124-131

Yoshioka S, Toda M, Nakajima J (2009) Regionality of deep low-frequency earthquakes associated with subduction of the Philippine Sea plate along the Nankai Trough, southwest Japan. Earth Planet Sci Lett 272:189-198. doi:10.1016/j.epsl.2008.04.039

Zhang H, Thurber CH (2003) Double-difference tomography: the method and its application to the Hayward fault, California. Bull Seismol Soc Am 93:1875-1889. doi:10.1785/0120020190

doi:10.1186/1880-5981-66-86

Cite this article as: Kato et al:: Non-volcanic seismic swarm and fluid transportation driven by subduction of the Philippine Sea slab beneath the Kii Peninsula, Japan. Earth, Planets and Space 2014 66:86. 